\title{
Correction to: System-Wide Pollution of Biomedical Data: Consequence of the Search for Hub Genes of Hepatocellular Carcinoma Without Spatiotemporal Consideration
}

\author{
Ankush Sharma ${ }^{1,2,4}\left(\right.$ D $\cdot$ Giovanni Colonna ${ }^{3}$
}

Accepted: 7 April 2021 / Published online: 5 May 2021

c) Springer Nature Switzerland AG 2021

\section{Correction to: \\ Molecular Diagnosis \& Therapy (2021) 25:9-27 \\ https://doi.org/10.1007/s40291-020-00505-3}

The article System-Wide Pollution of Biomedical Data: Consequence of the Search for Hub Genes of Hepatocellular Carcinoma Without Spatiotemporal Consideration written by Ankush Sharma, Giovanni Colonna, was originally published online on 21 January 2021 with Open Access under "Creative Commons Attribution Non-Commercial (CC BY-NC 4.0)".

\begin{abstract}
After publication in volume 25, issue 1, page 9-27 the author(s) decided to cancel the Open Access. Therefore, the copyright of the article has been changed on 28-04-2021 to (C) Springer Nature Switzerland AG 2020 with all rights reserved.
\end{abstract}

The original article can be found online at https://doi.org/10.1007/ s40291-020-00505-3.

Ankush Sharma

ankush.sharma@ibv.uio.no; ankush.sharma@medisin.uio.no

1 Department of Biosciences, University of Oslo, Oslo, Norway

2 Department of Informatics, University of Oslo, Oslo, Norway

3 Medical Informatics, AOU-Vanvitelli, Università della Campania, Naples, Italy

4 Present Address: Institute of Cancer Research, Institute of Clinical medicine, University of Oslo, Oslo, Norway 